\title{
Effects of CD133 expression on chemotherapy and drug sensitivity of adenoid cystic carcinoma
}

\author{
LIAN ZHOU, YING SUN, GUO YE, YANGUANG ZHAO and JIAN WU \\ Chongqing Key Laboratory of Translational Research for Cancer Metastasis and Individualized Treatment, \\ Chongqing University Cancer Hospital, Chongqing 400030, P.R. China
}

Received March 5, 2021; Accepted July 9, 2021

DOI: $10.3892 / \mathrm{mmr} .2021 .12534$

\begin{abstract}
The cellular resistance of tumors is a major obstacle for successful tumor therapy. Cluster of differentiation (CD)133 plays an important role in the regulation of drug resistance in gastric and colon cancers. However, its effect on chemotherapeutic sensitivity in adenoid cystic carcinoma (ACC) has not been fully explored. The present study discussed the specific role of CD133 in ACC drug-resistant sensitive cells. KOA-1 cells were treated with 5-fluorouracil (5-FU) and pingyangmycin (PYM) to form drug-resistant cell lines. A Cell Counting Kit-8 assay was used to detect the cell survival rate. Cell invasion was measured using a Transwell assay. The expression levels of CD133 were detected by reverse transcription-quantitative (RT-q) PCR. The expression levels of drug-resistant mRNAs and proteins were detected by RT-qPCR and immunofluorescence analyses, respectively. The CD133 were inhibited by small interfering RNA technology. The survival rate and invasive ability of KOA-1 cells were increased following the induction of drug resistance. The expression levels of CD133, multidrug resistance protein (MDR)1 and multidrug resistance-associated protein (MRP)1 were significantly increased in drug-resistant cell lines. Knockdown of CD133 expression in the resistant cell lines, KOA-1/5-FU and KOA-1/PYM, decreased the survival rate and invasive ability. The expression levels of MDR1 and MRP1 were also significantly decreased. Knockdown of CD133 expression in ACC drug-resistant cells could inhibit the viability and invasion of tumors and enhance the sensitivity of drug-resistant cells to chemotherapeutic drugs.
\end{abstract}

Correspondence to: Dr Jian Wu, Chongqing Key Laboratory of Translational Research for Cancer Metastasis and Individualized Treatment, Chongqing University Cancer Hospital, 181 Hanyu Road, Shapingba, Chongqing 400030, P.R. China

E-mail: wujian2223@126.com

Key words: cluster of differentiation 133, adenoid cystic carcinoma, chemotherapy drug sensitivity

\section{Introduction}

Adenoid cystic carcinoma (ACC) is one of the most common types of cancers of the salivary gland. A previous study showed that $\mathrm{ACC}$ is more frequently found in exocrine glands, such as the lacrimal gland, nasal cavity, tracheobronchial tree and prostate (1). ACC grows slowly and is usually diagnosed at the advanced stage of the disease (2). However, ACC may expand and gradually metastasize along the nerves, which affects its resection and the success of clinical surgery $(3,4)$. In addition, drug resistance of ACC is commonly noted for various chemotherapeutic drugs, which affects the efficacy of treatment and causes discomfort to patients with this disease (5).

Cluster of differentiation (CD)133 was initially identified as a potential marker of tumor stem cells (6). Previous studies have shown that CD133 can regulate cell proliferation and differentiation and promote tumor growth and metastasis $(7,8)$. CD133 may be used as a marker of various stem and tumor cells and can mediate cell signaling transduction. CD133 activates the PI3K/AKT, AKT/Wnt and other signaling pathways and affects the behavior of $\mathrm{CD} 133^{+}$cells, thereby playing a major role in cancer therapy $(9,10)$. In addition, CD133 is also involved in the regulation of tumor resistance. Long-term chemotherapy leads to a significant increase in CD133 expression (11). Targeting CD133 can reverse drug resistance in colorectal cancer via the $\mathrm{AKT} / \mathrm{NF}-\kappa \mathrm{B} /$ multidrug resistance protein (MDR)1 pathway (12). In gastric cancer, inhibition of CD133 overcomes 5-fluorouracil (5-FU) resistance by inhibiting the PI3K/AKT/mTOR signaling pathway and the autophagy of $\mathrm{CD}_{133^{+}}$gastric cancer cells (10). Therefore, CD133 can affect the cellular resistance of tumor cells. However, to the best of the authors' knowledge, the effects of $\mathrm{CD} 133$ on cell drug resistance in ACC have not been reported to date.

It has been shown that CD133 is highly expressed in $\mathrm{ACC}$ cells (13). In tumor samples from patients with ACC, the positive expression of CD133 is correlated with vasculogenic mimicry formation, local recurrence, distant metastasis and poor prognosis and it has been demonstrated that $\mathrm{CD} 133^{+}$ tumor stem cell-like cells promote the migration and invasion of ACC cells and induce vasculogenic mimicry formation (14). However, the effects of CD133 on the sensitivity of ACC cells to drugs and its precise mechanism remain to be elucidated. 
In the present study, the association between the expression levels of CD133 in ACC and the sensitivity of cancer cells to chemotherapeutic drugs was assessed and the mechanism involved in this process was investigated. These results may provide a theoretical basis for improving the efficacy of ACC chemotherapeutic treatment.

\section{Materials and methods}

Cell culture. The ACC cell line KOA-1 was purchased from The Cell Bank of Type Culture Collection of The Chinese Academy of Sciences. The cells were incubated in DMEM supplemented with $10 \%$ FBS (both from Gibco; Thermo Fisher Scientific, Inc.) at $37^{\circ} \mathrm{C}$ with $5 \% \mathrm{CO}_{2}$. The drug-resistant cell strains KOA-1/5-FU and KOA-1/PYM (pingyangmycin) were purchased from Shanghai Gefan Biotechnology Co., Ltd. The KOA-1/5-FU and KOA-1/PYM cell lines were generated by an intermittent and stepwise method (15). In brief, the parental KOA-1 cells were initially incubated with 5-FU and PYM (the concentration of 5-FU and PYM used were the $\mathrm{IC}_{50}$ ) for 4 days, and then cultured in drug-free medium for 3-4 days at $37^{\circ} \mathrm{C}$ until the recovery of normal cell viability. The 5-FU and PYM treatment was performed six times during the induction period, and then 5-FU and PYM -resistant clones were harvested. Drug resistance was maintained in KOA-1/5-FU and KOA-1/PYM cells by supplementation of culture media with 5-FU and PYM at a final concentration of $2 \mathrm{nmol} / \mathrm{l}$.

Western blotting. Total protein from cells were extracted using RIPA lysis buffer (Beijing Solarbio Science \& Technology Co., Ltd.). The protein concentration was determined with the application of a BCA assay kit (Beyotime Institute of Biotechnology). Afterwards, 10\% SDS-PAGE gels were prepared to separate proteins (30 $\mu \mathrm{g}$ each lane), and then the latter were transferred onto polyvinylidene difluoride (PVDF) membranes (EMD Millipore). Then, the PVDF membrane was fixed with $5 \%$ skimmed milk powder at room temperature for $1.5 \mathrm{~h}$. PVDF membranes were incubated with primary antibodies, including anti-CD133 (1:1,000; cat. no. ab222782; Abcam), anti-MDR1 (1:1,000; cat. no. ab235954; Abcam), anti-MRP1 (1:1,000; cat. no. ab3368; Abcam) and anti-GAPDH (1:1,000; cat. no. ab8245; Abcam), and were removed the second day. In addition, goat anti-mouse IgG antibody (1:5,000, cat. no. AP127F; Sigma-Aldrich; Merck KGaA) were prepared for incubation with PVDF membranes at room temperature for $1.5 \mathrm{~h}$. The protein bands were visualized and analyzed using a chemiluminescence system (Bio-Rad Laboratories, Inc.) and semi-quantified using ImageJ software (version 1.46; National Institutes of Health).

Cell Counting Kit-8 (CCK-8) assay. The CCK-8 assay (Dojindo Molecular Technologies, Inc.) was used to measure cell viability. The cells were seeded at a density of $1 \times 10^{4}$ cells per well into 96-well plates. The cells were transfected and treated with 5-FU or PYM. Then, a total of $10 \mu \mathrm{l}$ CCK-8 solution was added to the cells, which were incubated at $37^{\circ} \mathrm{C}$ for $4 \mathrm{~h}$. The absorbance was subsequently measured at $450 \mathrm{~nm}$ using a microplate reader (Molecular Devices, LLC).

Wound healing assay. Cell migration was determined using a wound healing assay. Briefly, transfected cells were plated in 12-well plates at a density of $1 \times 10^{5}$ cells/well. Once cells reached $80 \%$ confluence, the medium was replaced with serum-free DMEM and cells were incubated at $37^{\circ} \mathrm{C}$ overnight before initiating the experiment. Subsequently, a wound was created on the surface of the cell monolayer using a $200-\mu 1$ pipette tip. The cells were then rinsed twice with serum-free medium in order to remove free-floating cells and debris. An inverted light microscope (magnification, x200; BX51; Olympus Corporation) was used to monitor cells at the edges of the scratch. The percentage of wound closure was determined according to the following equation: [(Ai-At)/Ai] x100, where Ai represented the initial area of the wound at $0 \mathrm{~h}$ and At represented the area of the wound after $24 \mathrm{~h}$.

Transwell assay. The invasion assay was performed by precoating the upper chambers of 24-well Transwell plates (8- $\mu \mathrm{m}$ pore size) with Matrigel (Sigma-Aldrich; Merck KGaA), according to the manufacturer's instructions. Cell suspensions were then added to the Transwell chambers at a density of $1-1.5 \times 10^{6}$ cells $/ \mathrm{ml}$. The lower chamber was filled with $0.5 \mathrm{ml}$ DMEM containing FBS. The cells were incubated for $24 \mathrm{~h}$ at $37^{\circ} \mathrm{C}$, then the cells remaining in the upper chamber were removed using cotton swabs. The invasive cells in the lower chamber were fixed with paraformaldehyde for $15 \mathrm{~min}$ at room temperature and stained with $0.1 \%$ crystal violet for $30 \mathrm{~min}$ at room temperature. Finally, the cells were counted using a light microscope (magnification, x200).

Reverse transcription-quantitative PCR $(R T-q P C R)$. Total RNA was extracted from cells $\left(3 \times 10^{4}\right.$ cells/well) using TRIzol ${ }^{\circledR}$ reagent (Invitrogen; Thermo Fisher Scientific, Inc.) and an Invitrogen SuperScript ${ }^{\mathrm{TM}}$ III Reverse Transcriptase kit (Thermo Fisher Scientific, Inc.) was used for first-strand cDNA synthesis. The mRNA levels were quantified in triplicate using a real-time PCR system with the Brilliant SYBR-Green qPCR Kit (Stratagene; Agilent Technologies, Inc.). The aforementioned steps were performed following the manufacturer's instructions. The sequences of the primers were as follows: CD133 (sense, 5'-GGA TTATTCTATGCTGTGTCCTG-3' and antisense, 5'-TGCCACA AAACCATAGAAGAT-3'), MDR1 (sense, 5'-CTCGTGCCCTT GTTAGACAGCCTCAT-3' and antisense, 5'-GATGCGTGCC ATGCTCCTTGACTCT-3'), multidrug resistance-associated protein (MRP)1 (sense, 5'-GAGTGGCG GTGATGGTCCTCAT GGT-3' and antisense, 5'-CACGGCTG ACAGGTAGGCAGACT TCT-3'), GAPDH (sense, 5'-AGTGGTGGACCTGACCTGCCGT CTA-3' and antisense, 5'-GGAGGA GTGGGTGTCGCTGTTGA AGT-3'). The following PCR thermocycling conditions were used: $10 \mathrm{~min}$ at $95^{\circ} \mathrm{C}$; followed by 47 cycles at $95^{\circ} \mathrm{C}$ for $30 \mathrm{sec}, 60^{\circ} \mathrm{C}$ for $30 \mathrm{sec}$ and $72^{\circ} \mathrm{C}$ for $60 \mathrm{sec}$. Expression was determined by the $2^{-\Delta \Delta \mathrm{Cq}}$ method (16). The experiment was repeated three times.

Immunofluorescence (IF) staining. The cells were seeded at a density of $4 \times 10^{4}$ cells/well into 6-well plates and incubated overnight. The cells were treated with the indicated concentrations, fixed using $4 \%$ formaldehyde for $30 \mathrm{~min}$ at $25^{\circ} \mathrm{C}$ and treated with $3 \%$ bovine serum albumin (BSA; Thermo Fisher Scientific, Inc.) in phosphate buffered saline for $30 \mathrm{~min}$. The coverslips were incubated with rabbit anti-MDR1 (1:200; cat. no. ab235954; Abcam) and anti-MRP1 antibodies (1:200; cat. no. ab3368; Abcam) at $4^{\circ} \mathrm{C}$ overnight diluted in $3 \%$ BSA. Subsequently, an 

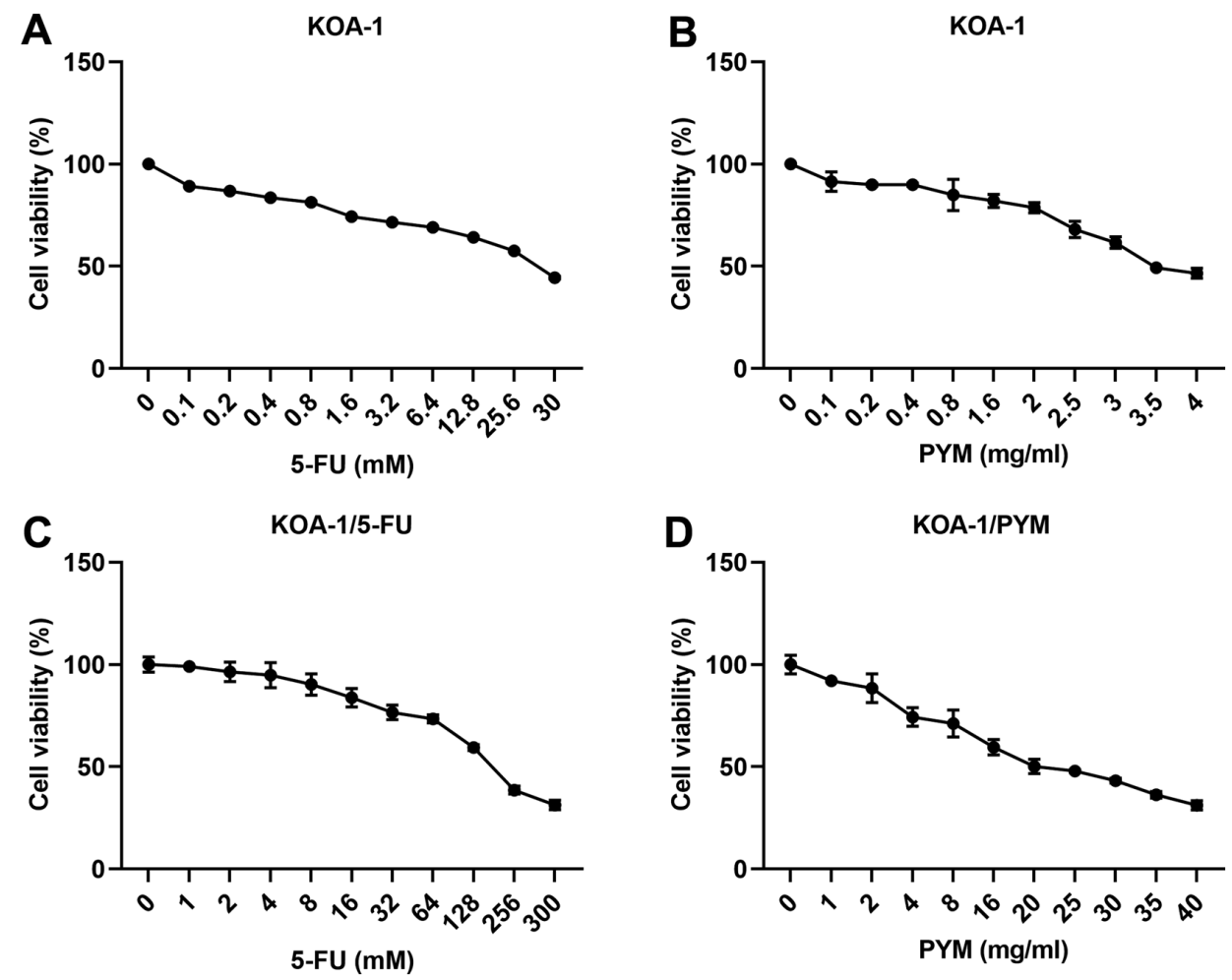

Figure 1. Drug-resistant cell lines exhibit significantly increased survival ability. (A) CCK-8 detected the cell viability of KOA-1 cells induced by 5-FU. (B) CCK-8 detected the cell viability of KOA-1 cells induced by PYM. (C) CCK-8 detected the cell viability of KOA-1/5-FU cells induced by 5-FU. (D) CCK-8 detected the cell viability of KOA-1/PYM cells induced by PYM. 5-FU, 5-fluorouracil; PYM, pingyangmycin; CCK-8, Cell Counting Kit-8.

immunofluorescent antibody (1:500; cat. no. A-21072; Alexa Fluor; Invitrogen; Thermo Fisher Scientific, Inc.) was incubated with the cells at $37^{\circ} \mathrm{C}$ for $2 \mathrm{~h}$. DAPI was added to cells and incubation was performed in the dark for $5 \mathrm{~min}$ at room temperature. The cells were visualized using a fluorescence microscope equipped with appropriate filter sets (magnification, x200; Zeiss $\mathrm{GmbH}$ ). Negative controls contained cells without conjugated antibodies. The integrated optical density values, which represented the staining intensity, were calculated for the acquired images using Image-Pro Plus 6.0 (Media Cybernetics, Inc.).

Small interfering RNA (siRNA) transfection. siRNAs were synthesized and purified by Shanghai GenePharma Co., Ltd. The transfection of siRNA CD133\#1 and siRNA CD133\#2 was performed using Lipofectamine ${ }^{\circledR} 2000$ reagent (Invitrogen; Thermo Fisher Scientific, Inc.) following the manufacturer's instructions at a final concentration of $100 \mathrm{nmol} / \mathrm{l}$. The transfection of siRNA negative control (NC) was performed using the same conditions. The sequences used were: CD133\#1 siRNA, 5'-GGCAGAUAGCAAUUUCAAGGACUTG-3'; CD133\#2 siRNA, 5'-GGCUUGGAAUUAUGAAUUGCCU GCA-3'; and siRNA-NC,5'-UUCUCCGAACGUGUCACGU-3'. Follow-up experiments were conducted $48 \mathrm{~h}$ after transfection.

Statistical analysis. SPSS version 21.0 (IBM Corp.) was used to perform all statistical analyses and the data are presented as the mean \pm standard deviation. Statistical comparisons between groups were made using a one-way ANOVA followed by a Tukey's post hoc test. $\mathrm{P}<0.05$ was considered to indicate a statistically significant difference. Each experiment was repeated three times.

\section{Results}

Drug-resistant cell lines exhibit significantly increased survival and invasive ability. The CCK-8 assay was used to detect the effects of 5-FU and PYM on the survival rate of KOA-1 cells and the corresponding drug-resistant cell types. As shown in Fig. $1 \mathrm{~A}-\mathrm{D}$, the $\mathrm{IC}_{50}$ value of $5-\mathrm{FU}$ in $\mathrm{KOA}-1$ cells was estimated to be $25 \mathrm{mM}$, while that of $5-\mathrm{FU}$ in KOA-1/5FU cells was estimated to be $150 \mathrm{mM}$, indicating a significant increase in the drug resistance of KOA-1/5-FU and KOA-1/PYM cells. The effects of PYM on KOA-1 cells and the corresponding drug-resistant cell types were consistent with the results noted following treatment of the cells with 5-FU. Subsequently, western blotting was used to detect the expression of CD133 and CD133 was increased in KOA-1/5-FU and KOA-1/PYM cells compared with that of KOA-1 cells (Fig. 2A) the wound healing and Transwell assay was used to detect the migration and invasive ability of the cells. The results indicated that the migration and invasive activity of KOA-1/5-FU and KOA-1/PYM cells was significantly increased compared with that of KOA-1 cells, suggesting that cell resistance and the migration and invasive activity of KOA-1/5-FU and KOA-1/PYM-resistant cell lines were significantly increased (Fig. 2B and C). The results showed that drug-resistant cell lines exhibit significantly increased survival, migration and invasive ability.

CD133 expression is associated with the drug sensitivity of tumor cells. Subsequently, RT-qPCR analysis was used to detect the expression levels of CD133 in KOA-1 cells and their drug-resistant cell types. CD133 expression levels were significantly increased 

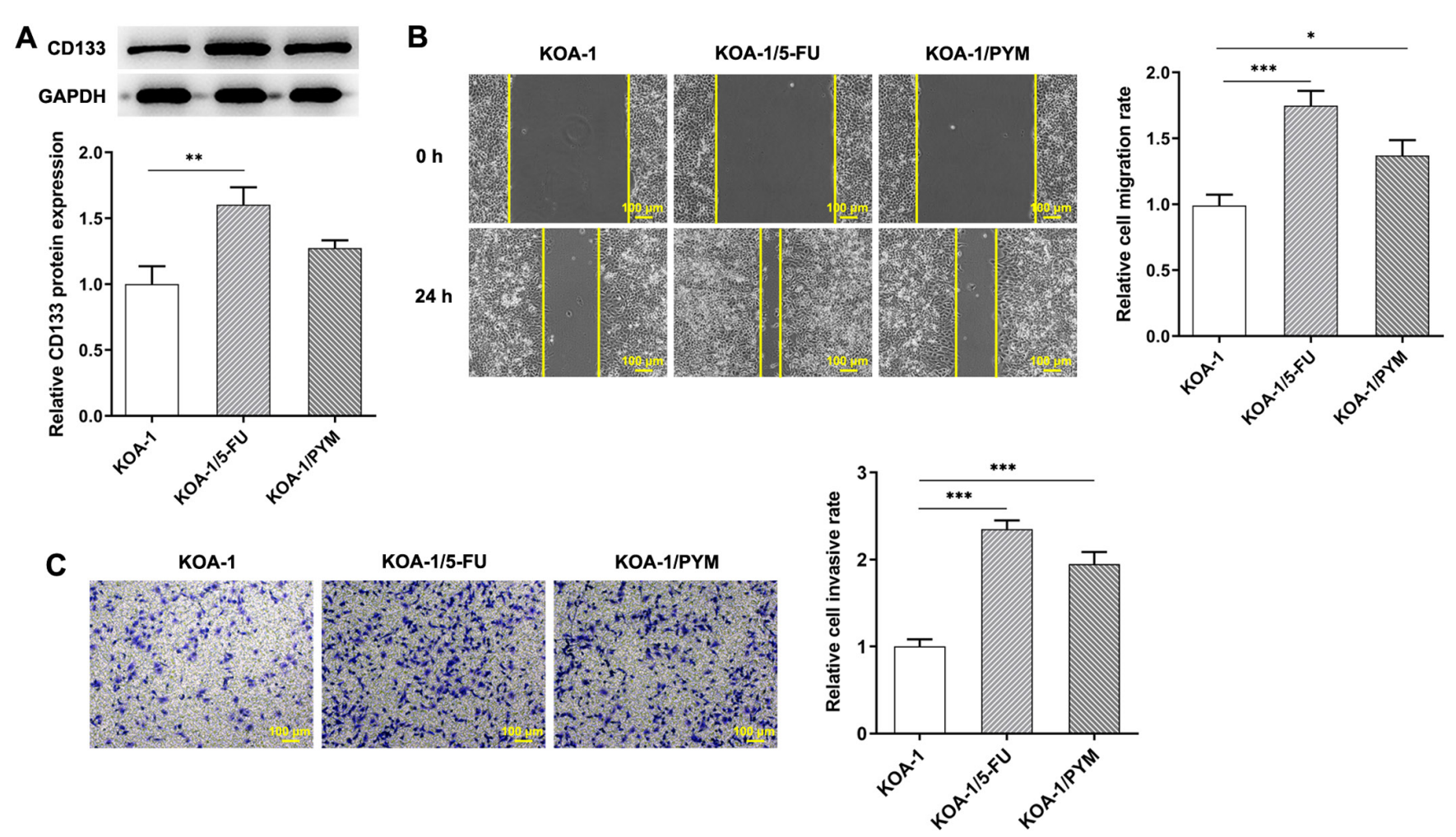

Figure 2. Drug-resistant cell lines exhibit significantly increased invasive ability. (A) Western blotting was performed to detect the expression of CD133. (B) Wound healing assay detected the migration of drug-resistant cell lines. (C) Transwell assay detected the invasion of drug-resistant cell lines. ${ }^{*} \mathrm{P}<0.05$, ${ }^{* *} \mathrm{P}<0.01,{ }^{* * *} \mathrm{P}<0.001$. CD , cluster of differentiation; 5-FU, 5-fluorouracil; PYM, pingyangmycin.

in drug-resistant cell lines compared with those noted in KOA-1 cells (Fig. 3A). Subsequently, RT-qPCR and western blotting was used to detect the expression levels of the multidrug resistant proteins, MDR1 and MRP1, in the corresponding cell lines. The results indicated that the expression levels of MDR1 and MRP1 were significantly increased in KOA-1/5-FU and KOA-1/PYM cells compared with those of KOA-1 cells. The expression levels of MDR1 and MRP1 in KOA-1 cells were significantly decreased following treatment with 5-FU and PYM. However, the expression levels of MDR1 and MRP1 in KOA-1/5-FU and KOA-1/PYM cells treated with 5-FU and PYM, respectively, were not significantly altered, indicating that the drug resistance of KOA-1/5-FU (Fig. 3B and C) and KOA-1/PYM (Fig. 3D and E) cell lines was significantly increased. The expression levels of MDR1 and MRP1 were also detected by IF and the results were consistent with the results of the RT-qPCR assays (Fig. 4A and B). These results suggested a possible association between CD133 expression and the drug sensitivity of KOA-1 cells.

Knockdown of CD133 expression in drug-resistant cell lines inhibits cell viability and invasion. Cell transfection was used to knockdown the expression of CD133 in KOA-1 cells and a RT-qPCR assay was used to detect the transfection efficiency, as shown in Fig. 5A. siRNA CD133\#1 was selected for subsequent experiments. The siRNA CD133 plasmid was transfected into KOA-1, KOA-1/5-FU and KOA-1/PYM cells and a CCK-8 assay was used to detect cell viability. The data indicated that the viability of drug-resistant cell lines was higher than that of KOA-1 cells. Following inhibition of CD133 expression, the viability of KOA-1 cells and the drug-resistant cell lines, KOA-1/5-FU and KOA-1/PYM, were significantly decreased. Notably, the decrease observed in KOA-1/5-FU and KOA-1/PYM cells was higher than that of KOA-1 cells (Fig. 5B). Subsequently, a CCK-8 assay was used to detect cell viability following addition of the chemotherapeutic compounds, 5-FU and PYM. The $\mathrm{IC}_{50}$ of 5-FU on KOA-1/5-FU cells was lower than that on KOA-1 cells. Following interference of the expression of CD133, the inhibitory rate of 5-FU on KOA-1/5-FU cells (KOA-1/5-FU + siRNA CD133) was significantly increased compared with that of the corresponding negative control cells (KOA-1/5-FU + siRNA NC cells; Fig. 6A). The inhibitory rate of PYM was consistent with that of 5-FU (Fig. 6B). Wound healing and Transwell assays were used to detect the migration and invasive ability of the cells following inhibition of CD133 expression. Inhibition of CD133 expression significantly reduced the migration and cell invasive ability of KOA-1/5-FU and KOA-1/PYM cells (Fig. 7A and B). In addition, it was found that after 5-FU administration, the migration and invasion rate of $\mathrm{KOA}-1 / 5-\mathrm{FU}$ cells was significantly higher than that of KOA-1 cells. After the expression of CD133 was inhibited and 5-FU was administered, the migration and invasion rate of KOA-1/5-FU+siRNA CD133 cells was significantly decreased compared with KOA-1/5-FU +siRNA NC cells (Fig. 8A and B). The results indicated that inhibition of CD133 expression in drug-resistant cell lines significantly reduced the migratory and invasive abilities of drug-resistant cell lines. The results showed that the chemotherapeutic agents had a strong inhibitory effect on the viability and invasion ability of the knockdown CD133 resistant cell lines and that inhibiting the expression of CD133 could increase the sensitivity of ACC drug-resistant cells to chemotherapeutic agents. 
A

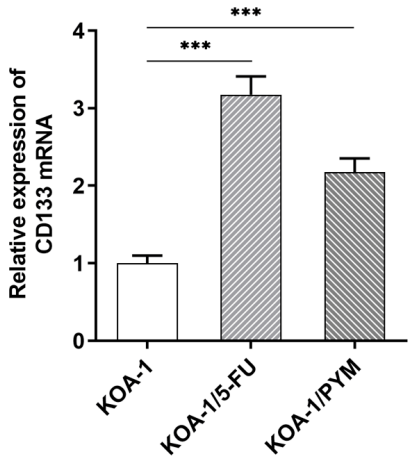

C

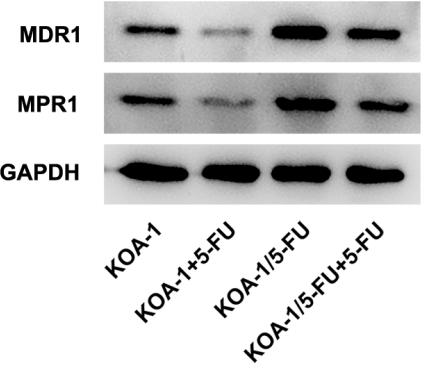

E

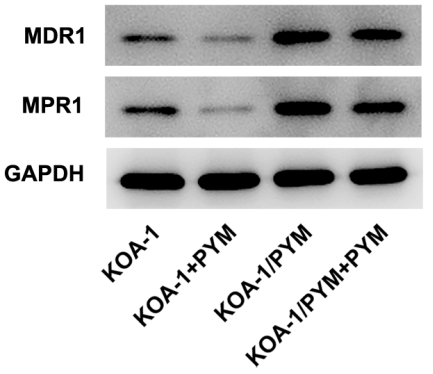

B
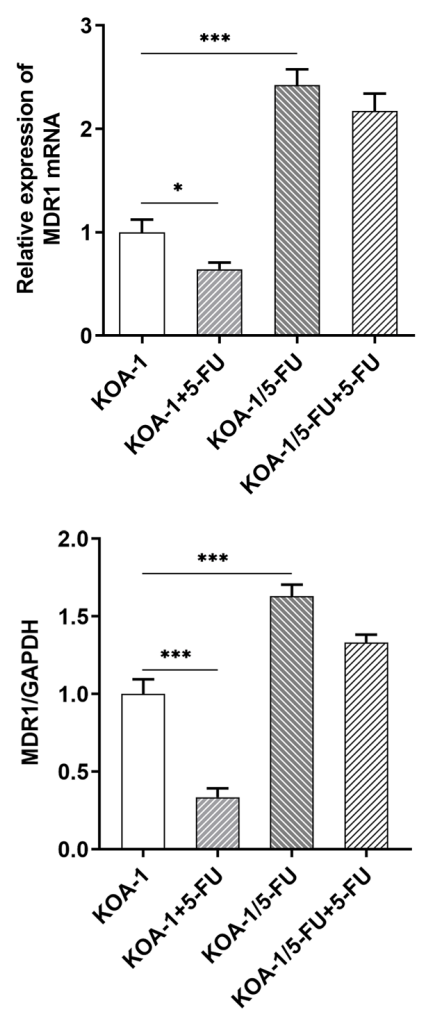

D
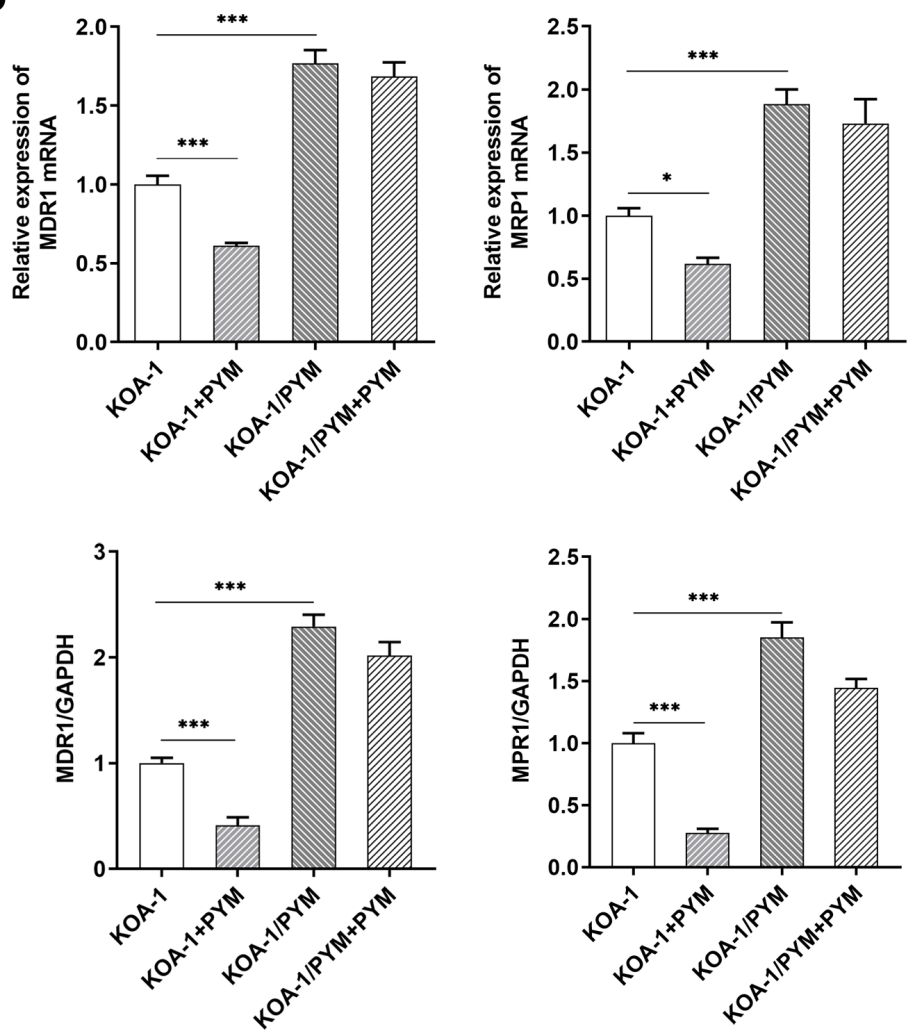
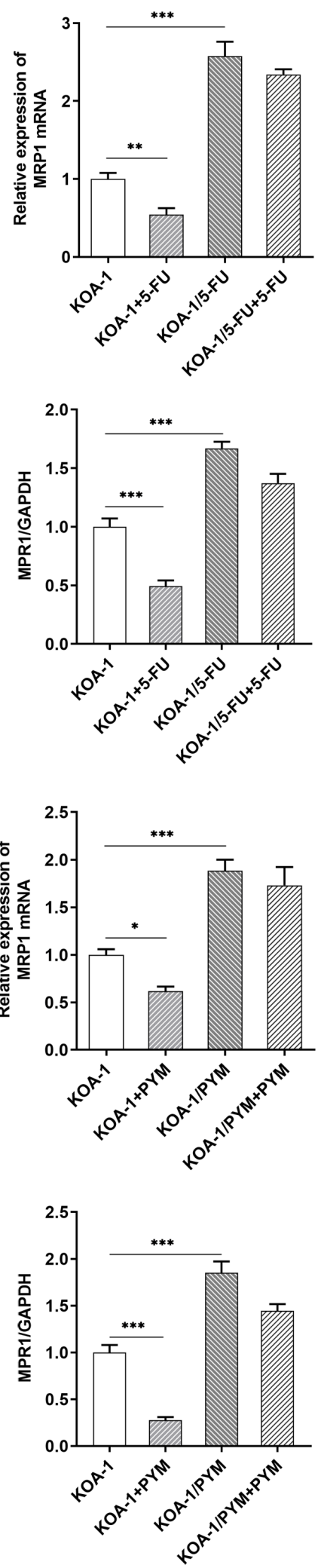

Figure 3. CD133 expression is associated with the drug sensitivity of tumor cells. (A) RT-qPCR was performed to detect the expression of CD133 in KOA-1/5-FU and KOA-1/PYM cells. RT-qPCR and western blotting were conducted to detect the expression of expression of drug-resistant associated mRNA and proteins in (B and C) KOA-1/5-FU and (D and E) KOA-1/PYM cells. ${ }^{*} \mathrm{P}<0.05,{ }^{* *} \mathrm{P}<0.01,{ }^{* * *} \mathrm{P}<0.001$. CD, cluster of differentiation; RT-qPCR, reverse transcription-quantitative PCR; 5-FU, 5-fluorouracil; PYM, pingyangmycin; MDR1, multidrug resistance protein 1; MRP1, multidrug resistance-associated protein 1.

Knockdown of CD133 expression in drug-resistant cell lines enhances cell sensitivity to chemotherapeutic drugs through inhibiting MDRI and MRP1. A RT-qPCR assay was used to detect the expression levels of CD133 in cells. The expression levels of CD133 in KOA-1/5-FU + siRNA CD133 cells were significantly decreased compared with those in the KOA-1/5-FU + siRNA NC group (Fig. 9A). The expression levels of MDR1 and MRP1 proteins were also decreased (Fig. 9B). The 

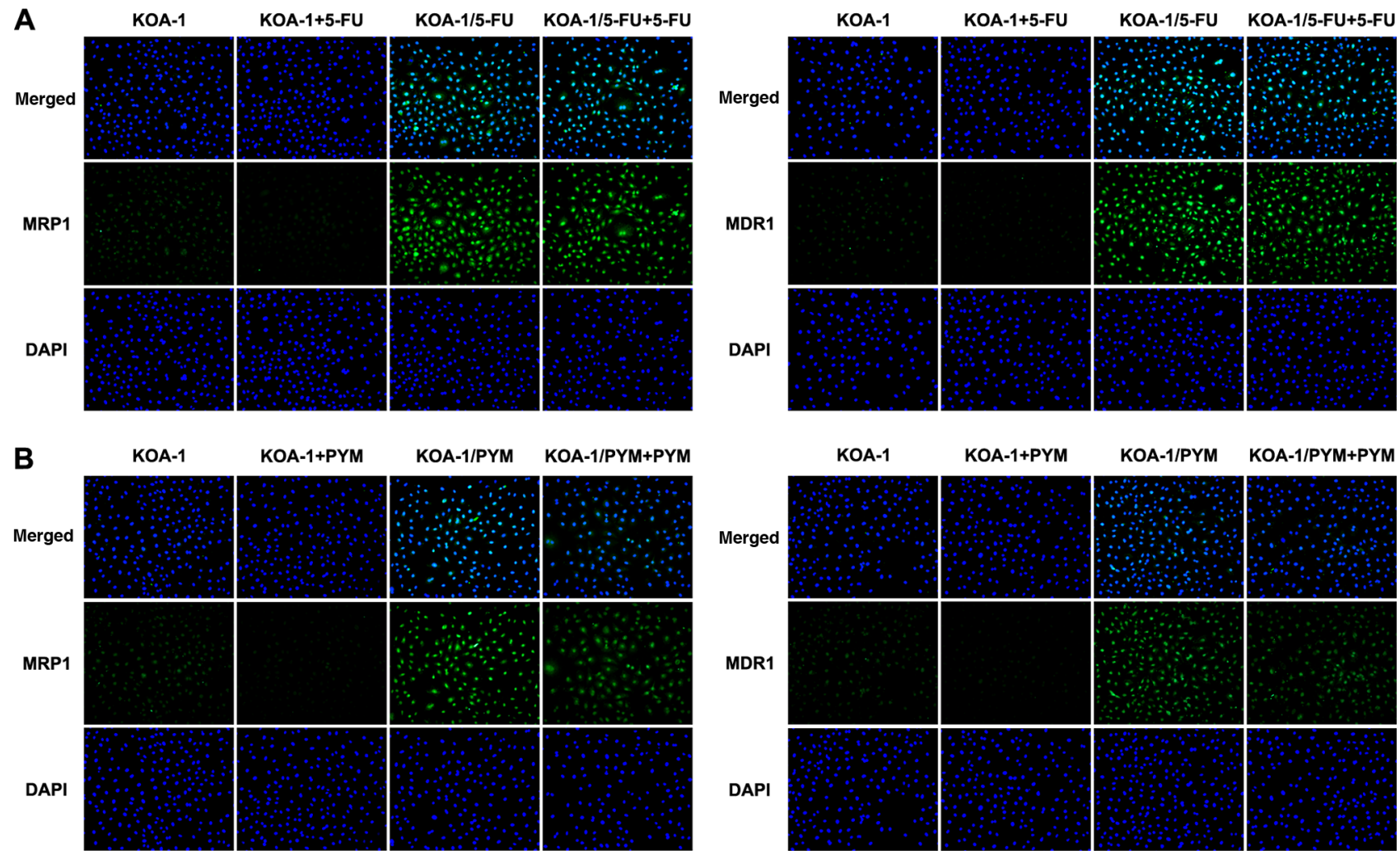

Figure 4. CD133 expression associated with the drug sensitivity of tumor cells. (A and B) The expression levels of multi-drug resistance proteins MDR1 and MRP1 were detected by immunohistochemistry. Magnification, x200. CD, cluster of differentiation; MDR1, multidrug resistance protein 1; MRP1, multidrug resistance-associated protein 1; 5-FU, 5-fluorouracil; PYM, pingyangmycin.
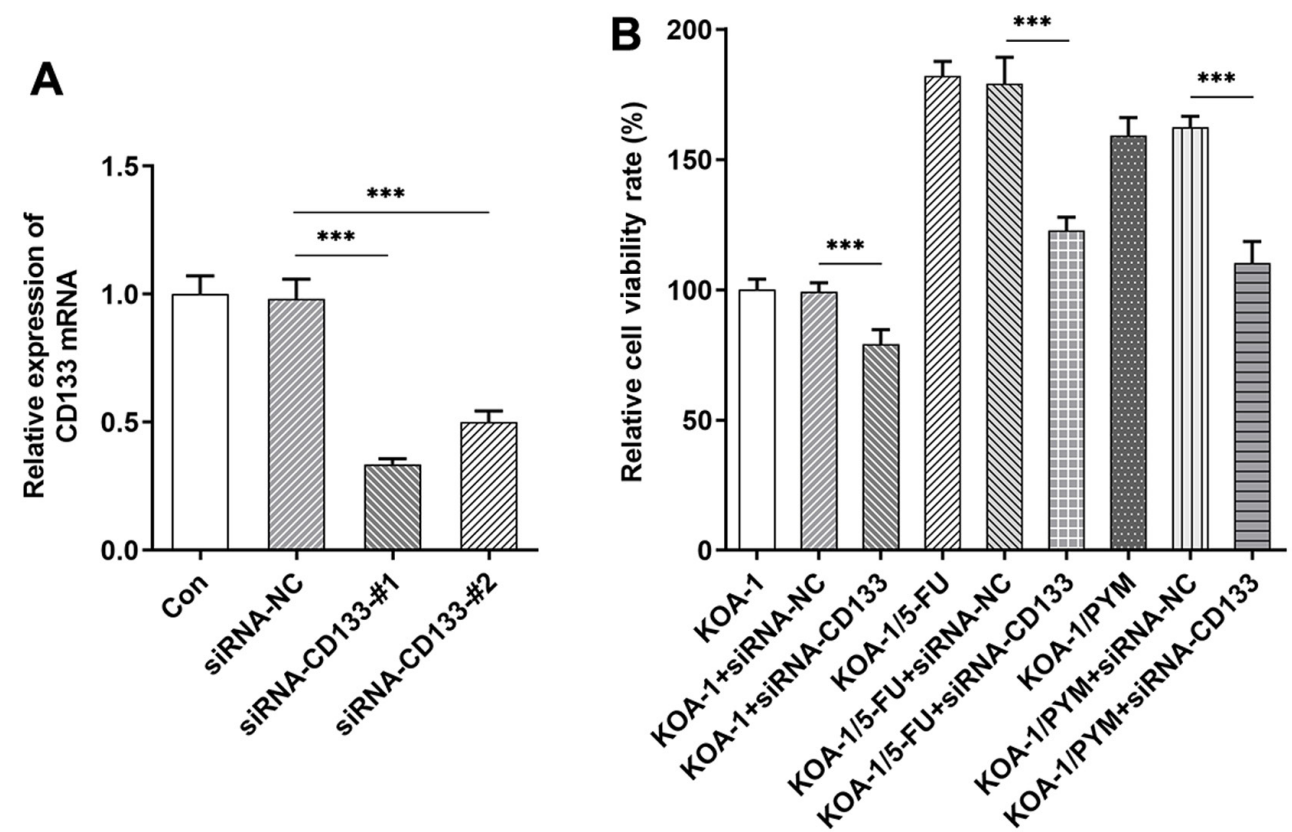

Figure 5. Cell viability after knockdown of CD133 expression in cells. (A) The expression of CD133 after cell transfection was detected by reverse transcription-quantitative PCR. (B) Cell Counting Kit-8 assay was performed to detect cell viability. ${ }^{* * * *} \mathrm{P}<0.001 . \mathrm{CD}$, cluster of differentiation; siRNA, small interfering RNA; NC, negative control; 5-FU, 5-fluorouracil; PYM, pingyangmycin.

expression pattern of these proteins in KOA-1/PYM cells was consistent with that noted in KOA-1/5-FU cells (Fig. 9C). The expression levels of MDR1 and MRP1 proteins were detected by IF and the results were consistent with the results of the
RT-qPCR assay (Fig. 10A and B). It was hypothesized that the knockdown of CD133 expression in drug-resistant cell lines may increase the cellular sensitivity to 5-FU and PYM through inhibiting MDR1 and MRP1. 

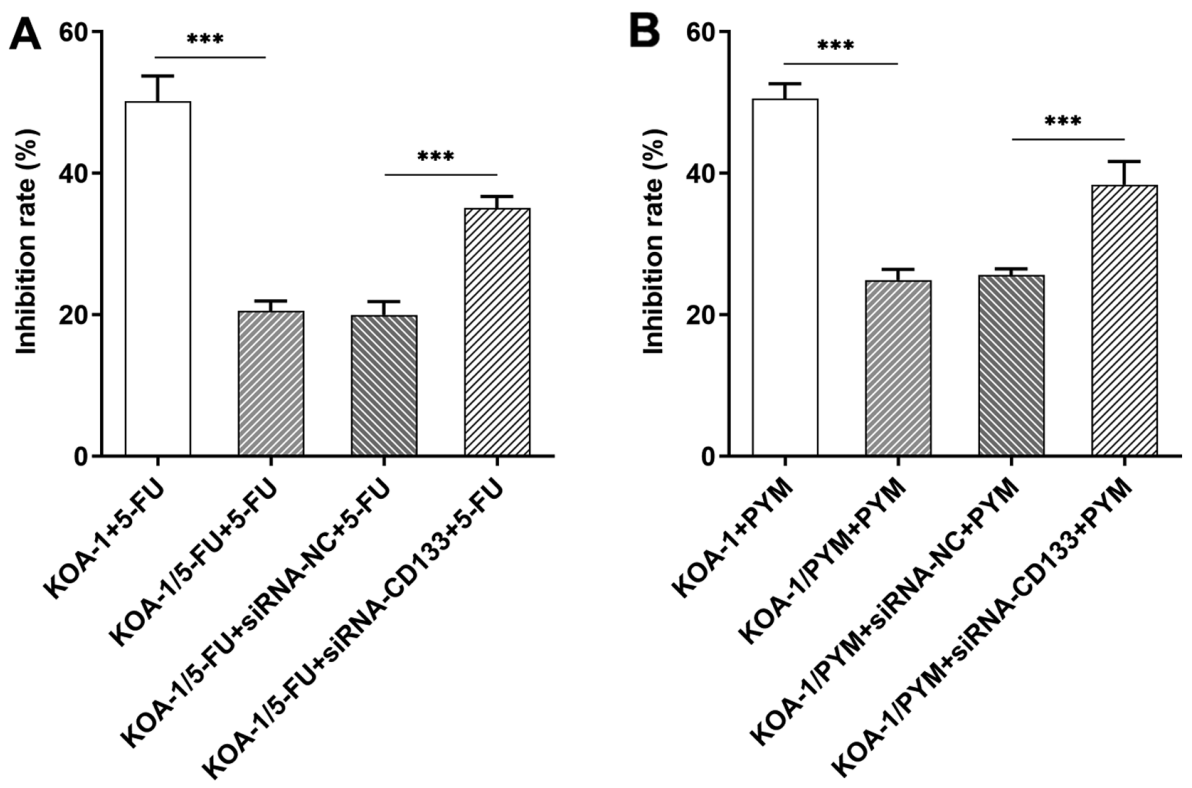

Figure 6. Knockdown of CD133 expression in drug-resistant cell lines inhibits cell viability. Cell Counting Kit-8 assay was used to detect cell inhibition after the addition of (A) 5-FU and (B) PYM. ${ }^{* * *} \mathrm{P}<0.001$. CD, cluster of differentiation; 5-FU, 5-fluorouracil; PYM, pingyangmycin; siRNA, small interfering RNA; $\mathrm{NC}$, negative control.

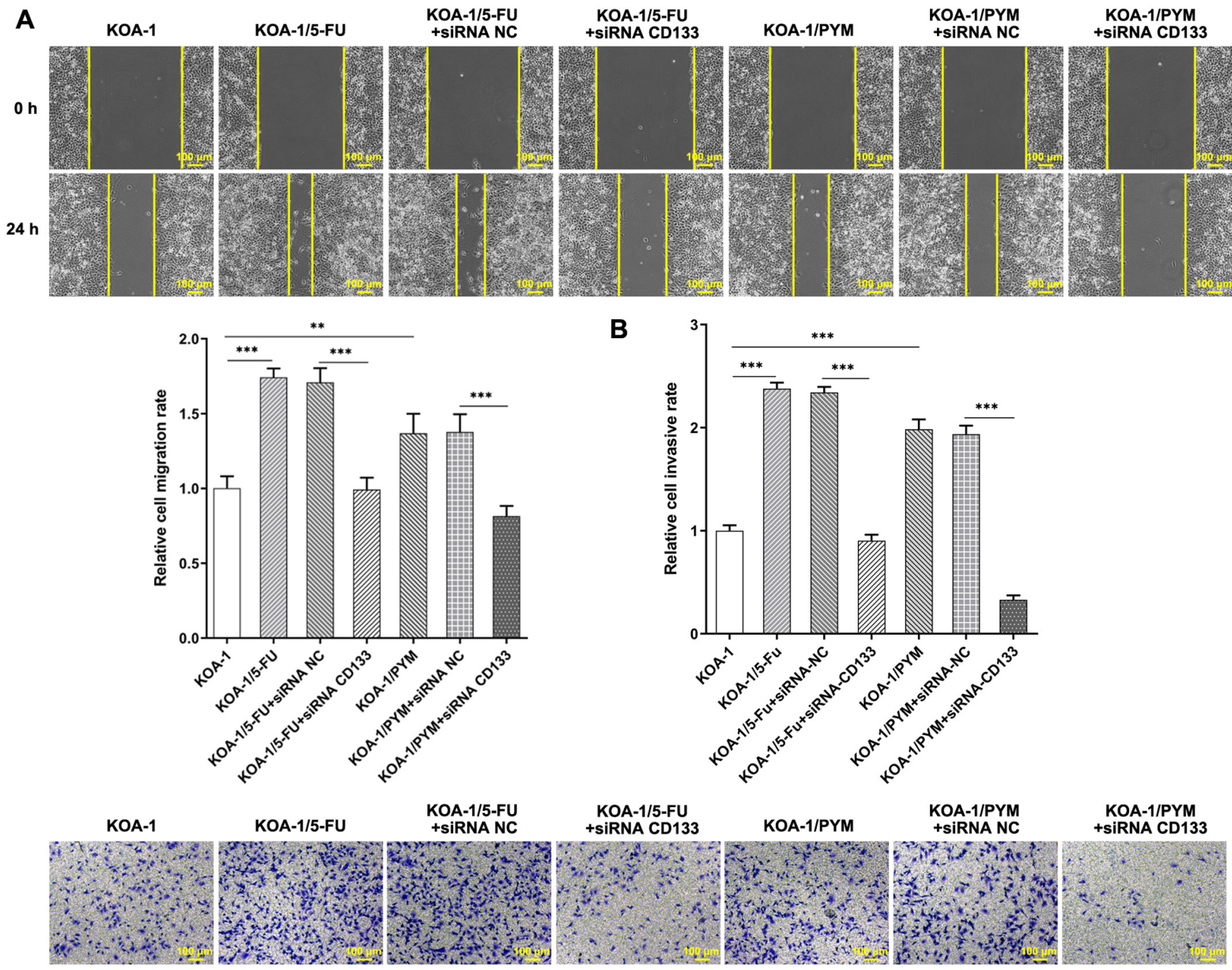

Figure 7. Knockdown of CD133 expression in drug-resistant cell lines inhibits cell invasion. (A) Wound healing assay detected the migration of drug-resistant cell lines. (B) Transwell assay detected the invasion of drug-resistant cell lines. Images and statistical chart of cell invasion rate. ${ }^{* * *} \mathrm{P}<0.01,{ }^{* * * *} \mathrm{P}<0.001$. CD, cluster of differentiation; 5-FU, 5-fluorouracil; PYM, pingyangmycin; siRNA, small interfering RNA; NC, negative control. 


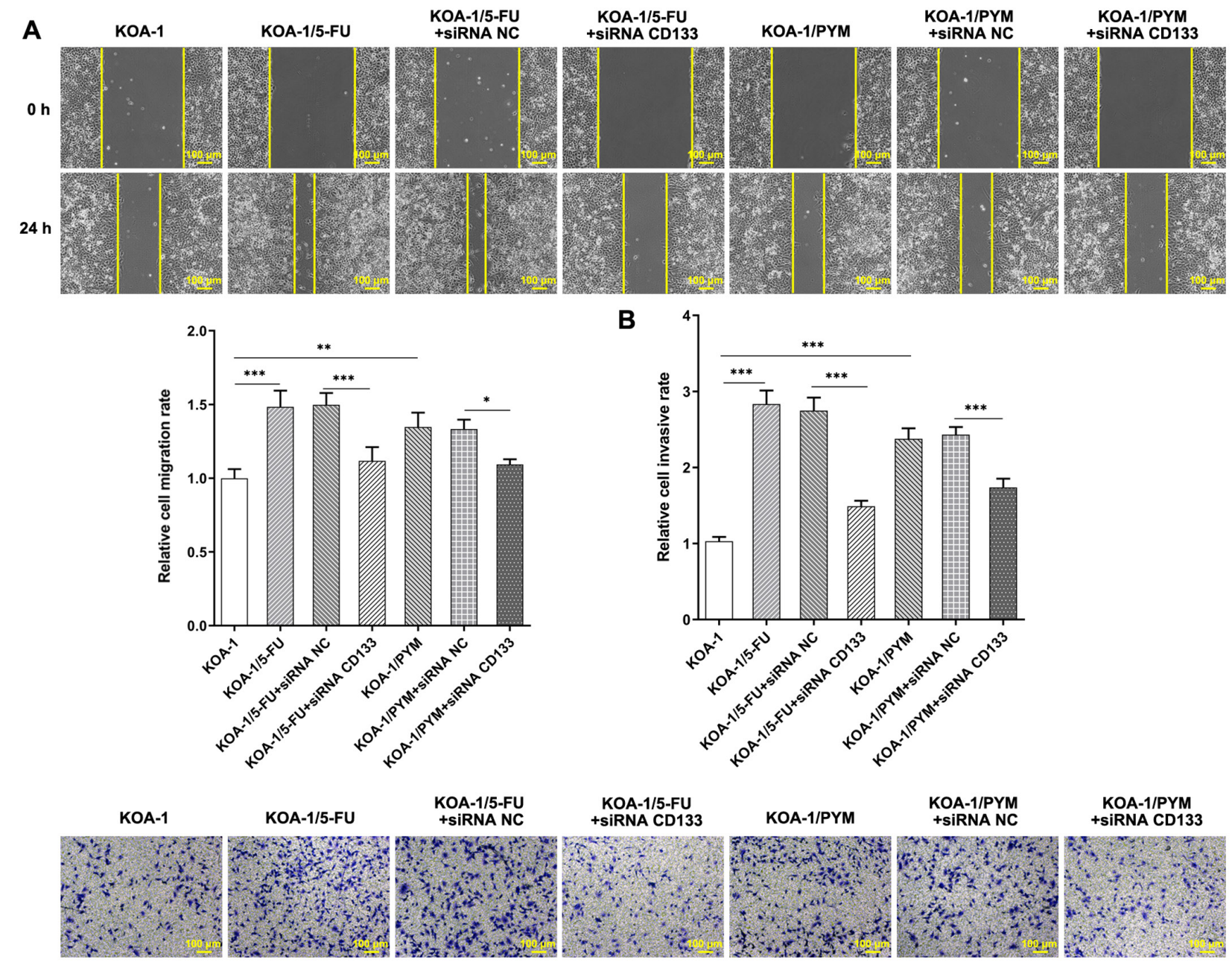

Figure 8. Knockdown of CD133 expression in drug-resistant cell lines inhibits cell invasion after treatment with chemotherapy drugs. (A) Wound healing assay detected the migration of drug-resistant cell lines. (B) Transwell assay detected the invasion of drug-resistant cell lines. Images and statistical chart of cell invasion rate. ${ }^{*} \mathrm{P}<0.05,{ }^{* * *} \mathrm{P}<0.01,{ }^{* * *} \mathrm{P}<0.001$. CD, cluster of differentiation; 5-FU, 5-fluorouracil; PYM, pingyangmycin; siRNA, small interfering RNA; NC, negative control .

\section{Discussion}

At present, the treatment of ACC mainly consists of surgical resection supplemented by chemotherapy. 5-FU and PYM are often used as chemotherapeutic drugs for the treatment of ACC $(17,18)$. However, repeated or long-term use of 5-FU and PYM is likely to cause cellular resistance in tumors, leading to a decline in chemotherapy efficacy and uncontrolled tumor growth (19). In Bi et al (20), CD133+ glioma stem cells isolated from the tumor tissue of glioma patients showed high expression of MDR1 and MRP1, suggesting that $\mathrm{CD} 133^{+}$brain tumor stem cells can be used as the root of multi-drug resistance and the key therapeutic target of glioma chemotherapy. In the present study, the data indicated that the migratory and invasive abilities of KOA-1/5-FU/PYM-resistant cell lines were significantly increased. The expression of MDR1 and MRP1 decreased, and the sensitivity to the drugs increased. The results indicated that the administration of chemotherapeutic drugs did not inhibit tumor growth following the development of cellular resistance. Therefore, it is imperative to identify effective and less toxic drugs for patients with tumors that have developed drug resistance.

CD133 is considered as an important marker of tumor stem cells and has been widely used in subpopulation sorting and their consequent identification (21). Accumulating evidence has shown that CD133 is involved in the regulation of specific biological characteristics of several tumor cells, including chemotherapy resistance $(22,23)$. Previous studies have shown that CD133 is associated with the development of chemotherapy resistance in lung, stomach, colon and liver cancers (24). CD133 expression has been used as a marker of tumor stem cells in small cell lung cancer and it has been shown that it is significantly associated with drug resistance and potent tumorigenicity. Further studies have shown that the proportion of $\mathrm{CD}_{133^{+}}$cells in small cell lung cancer is significantly increased following chemotherapy (25). A higher proportion of stem cells in acute myeloid leukemia at diagnosis is associated with a higher recurrence rate and the worse prognosis of patients following chemotherapy (26). In addition, in vivo tumor transplantation experiments using standard 5-FU-based chemotherapy regimens indicate that $\mathrm{CD} 133^{+}$and $\mathrm{CD} 24^{+}$ stem cells are enriched in patients with non-small cell lung cancer (27) and hepatocellular carcinoma (28), respectively. However, the association between CD133 expression and ACC drug resistance has not been previously reported.

In the present study, 5-FU and PYM were used to treat the ACC cell line, KOA-1, in order to establish 5-FU and PYM drug-resistant cell lines. A significant increase was noted in 


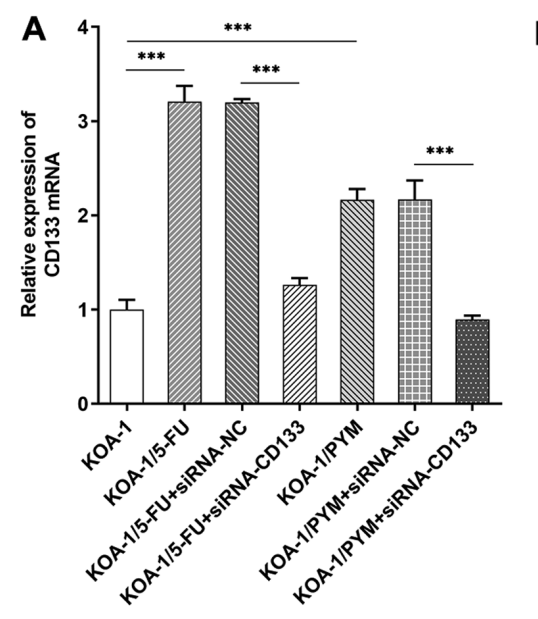

B
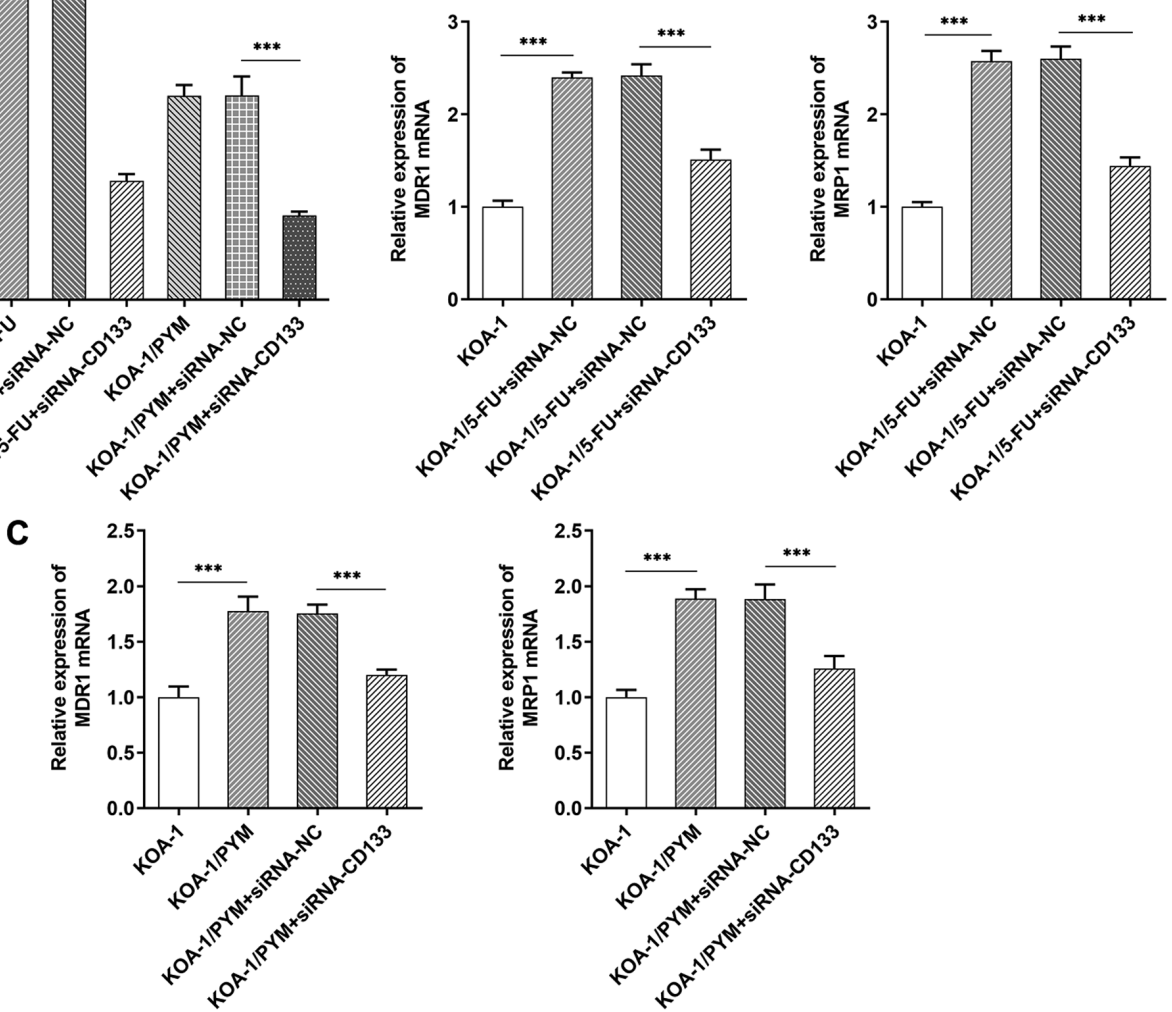

Figure 9. Knockdown of CD133 expression in drug-resistant cell lines enhances cell sensitivity to chemotherapy drugs. (A) RT-qPCR was performed to detect the expression of CD133. RT-qPCR detected the expression of drug-resistant associated genes in (B) KOA-1/5-FU and (C) KOA-1/PYM cells. ${ }^{* * * *} \mathrm{P}<0.001$. $\mathrm{CD}$, cluster of differentiation; RT-qPCR, reverse transcription-quantitative PCR; 5-FU, 5-fluorouracil; PYM, pingyangmycin; siRNA, small interfering RNA; NC, negative control; MDR1, multidrug resistance protein 1; MRP1, multidrug resistance-associated protein 1.
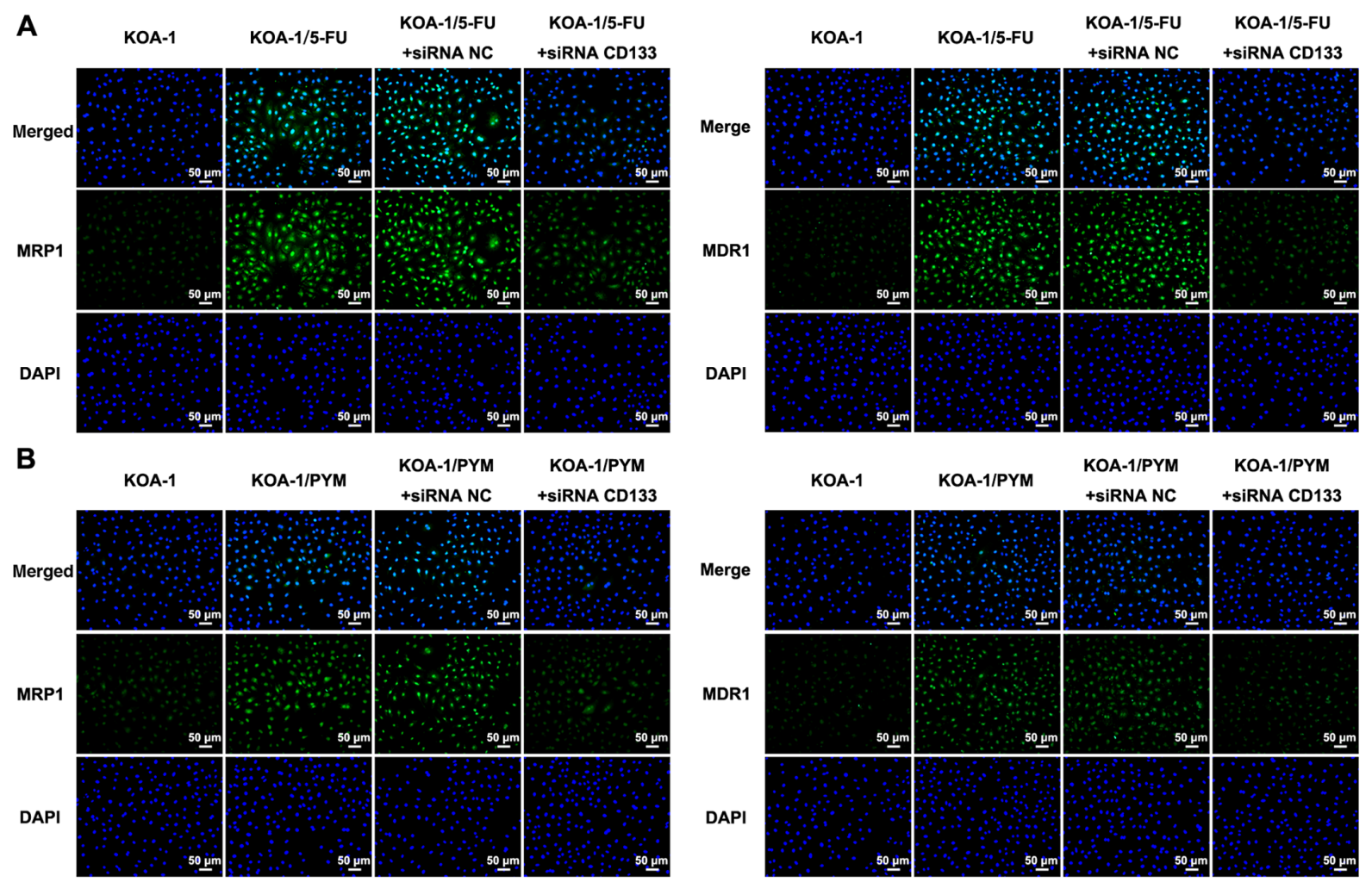

Figure 10. Knockdown of CD133 expression in drug-resistant cell lines enhances cell sensitivity to chemotherapy drugs. (A and B) The expression levels of multi-drug resistance proteins MDR1 and MRP1 were detected by immunohistochemistry. CD, cluster of differentiation; MDR, multidrug resistance protein; MRP, multidrug resistance-associated protein; 5-FU, 5-fluorouracil; PYM, pingyangmycin; siRNA, small interfering RNA; NC, negative control. 
CD133 expression in ACC-resistant cell lines. Inhibition of CD133 expression in drug-resistant cell lines inhibited the migratory and invasive abilities of drug-resistant cells and enhanced their sensitivity to chemotherapeutic drugs. These results suggested that CD133 serves an important role in the regulation of human ACC drug resistance and these are the main factors affecting the high morbidity and mortality in patients with ACC.

MDR1 and MRP1 are multi-drug resistant proteins, and their expressions can reflect the sensitivity of tumor cells to chemotherapy drugs (29). A previous study has shown that compared with CD133(-) glioblastoma stem cells, the protein expressions of MDR1 and MRP1 in CD133(+) cells are significantly increased (16). In the present study, the expression of CD133 was significantly increased in drug-resistant cell lines. When the expression of CD133 was inhibited, the expressions of MDR1 and MRP1 were also inhibited, which reduced the viability and migratory ability of drug-resistant cell lines, and increased the sensitivity of drug-resistant cell lines to drugs.

The present study contains certain limitations. The results were not confirmed by in vivo studies. The role of CD133 will be examined in the future in an ACC animal model and the associated mechanism will be further investigated. Only one ACC cell line was used in the present study, which may not be widely representative. The laboratory of the authors will conduct verification experiments in other ACC cell lines in the future. The present study proved the sensitivity of chemotherapeutic drugs by using only CCK- 8 to detect cell viability, without verifying cell apoptosis, which is also one of its limitations. Future studies will further detect the cell apoptosis to consolidate the conclusions of the present study. It might be also worth showing whether in the parental KOA-1 cells, inhibition of CD133 itself could result in inhibition of invasion ability, and compare with the drug-resistant lines. In addition, the present study only detected that CD133 has a regulatory effect on the drug resistance of 5-FU and PYM, but whether it has a regulatory effect on the drug resistance of all other drugs is still unknown. The present study detected endogenous CD133 expression, but the induction experiment of exogenous CD133 at different concentrations has not been carried out yet.

Overall, the present study demonstrated that knockdown of CD133 expression in drug-resistant cell lines enhances cell sensitivity to chemotherapeutic drugs through inhibiting MDR1 and MRP1. The data provide a theoretical basis for the prevention of drug resistance in ACC tumors.

\section{Acknowledgements}

Not applicable.

\section{Funding}

The present study was supported by the Chongqing City Committee of Science and Technology and Social Undertakings Livelihood Security Science and Technology Innovation Projects (grant no. cstc2016shmszx0770).

\section{Availability of data and materials}

The datasets used and/or analyzed during the current study are available from the corresponding author on reasonable request.

\section{Authors' contributions}

JW, LZ and YS wrote the manuscript and analyzed the data. GY and YZ performed the experiments and supervised the study. LZ searched the literature and revised the manuscript for important intellectual content. JW and LZ confirm the authenticity of all the raw data. All authors read and approved the final manuscript.

\section{Ethics approval and consent to participate}

Not applicable.

\section{Patient consent for publication}

Not applicable.

\section{Competing interests}

The authors declare that they have no competing interests.

\section{References}

1. Bradley PJ: Adenoid cystic carcinoma evaluation and management: Progress with optimism! Curr Opin Otolaryngol Head Neck Surg 25: 147-153, 2017.

2. Coca-Pelaz A, Rodrigo JP, Bradley PJ, Vander Poorten V, Triantafyllou A, Hunt JL, Strojan P, Rinaldo A, Haigentz M Jr, Takes RP, et al: Adenoid cystic carcinoma of the head and neck - An update. Oral Oncol 51: 652-661, 2015.

3. Castelnuovo P and Turri-Zanoni M: Adenoid cystic carcinoma. Adv Otorhinolaryngol 84: 197-209, 2020.

4. Gao M, Hao Y, Huang MX, Ma DQ, Luo HY, Gao Y, Peng X and Yu GY: Clinicopathological study of distant metastases of salivary adenoid cystic carcinoma. Int J Oral Maxillofac Implants 42: 923-928, 2013.

5. Ma B, Liang LZ, Liao GQ, Liang YJ, Liu HC, Zheng GS and Su YX: Inhibition of autophagy enhances cisplatin cytotoxicity in human adenoid cystic carcinoma cells of salivary glands. J Oral Pathol Med 42: 774-780, 2013.

6. Yu J, Tang Z, Gong W, Zhang M and Quan Z: Isolation and identification of tumor-initiating cell properties in human gallbladder cancer cell lines using the marker cluster of differentiation 133 . Oncol Lett 14: 7111-7120, 2017.

7. Hermann PC, Huber SL, Herrler T, Aicher A, Ellwart JW, Guba M, Bruns CJ and Heeschen C: Distinct populations of cancer stem cells determine tumor growth and metastatic activity in human pancreatic cancer. Cell Stem Cell 1: 313-323, 2007.

8. Li C, Wang C, Xing Y, Zhen J and Ai Z: CD133 promotes gallbladder carcinoma cell migration through activating $\mathrm{Akt}$ phosphorylation. Oncotarget 7: 17751-17759, 2016.

9. Manoranjan B, Chokshi C, Venugopal C, Subapanditha M, Savage N, Tatari N, Provias JP,Murty NK, Moffat J,Doble BW, et al: A CD133-AKT-Wnt signaling axis drives glioblastoma brain tumor-initiating cells. Oncogene 39: 1590-1599, 2020.

10. Lu R, Zhao G, Yang Y, Jiang Z, Cai J and Hu H: Inhibition of CD133 overcomes cisplatin resistance through inhibiting PI3K/ AKT/mTOR signaling pathway and autophagy in CD133-positive gastric cancer cells. Technol Cancer Res Treat: Jan 1, 2019 (Epub ahead of print). doi: 10.1177/1533033819864311.

11. Fayi MA, Alamri A and Rajagopalan P: IOX-101 Reverses drug resistance through suppression of Akt/mTOR/NF- $\mathrm{kB}$ signaling in cancer stem cell-like, sphere-forming NSCLC cell. Oncol Res 28: 177-189, 2020.

12. Yuan Z, Liang X, Zhan Y, Wang Z, Xu J, Qiu Y, Wang J, Cao Y, Le VM, Ly HT, et al: Targeting CD133 reverses drug-resistance via the AKT/NF- $\mathrm{BB} / \mathrm{MDR} 1$ pathway in colorectal cancer. Br J Cancer 122: 1342-1353, 2020.

13. Panaccione A, Zhang Y, Ryan M, Moskaluk CA, Anderson KS, Yarbrough WG and Ivanov SV: MYB fusions and CD markers as tools for authentication and purification of cancer stem cells from salivary adenoid cystic carcinoma. Stem Cell Res (Amst) 21: 160-166, 2017. 
14. Wang SS, Gao XL, Liu X, Gao SY, Fan YL, Jiang YP, Ma XR, Jiang J, Feng $\mathrm{H}$, Chen QM, et al: $\mathrm{CD} 133^{+}$cancer stem-like cells promote migration and invasion of salivary adenoid cystic carcinoma by inducing vasculogenic mimicry formation. Oncotarget 7: 29051-29062, 2016.

15. Panayotopoulou EG, Müller AK, Börries M, Busch H, Hu G and Lev S: Targeting of apoptotic pathways by SMAC or BH3 mimetics distinctly sensitizes paclitaxel-resistant triple negative breast cancer cells. Oncotarget 8: 45088-45104, 2017.

16. Livak KJ and Schmittgen TD: Analysis of relative gene expression data using real-time quantitative PCR and the 2(-Delta Delta C(T)) method. Methods 25: 402-408, 2001.

17. Cherifi F, Rambeau A, Johnson A, Florescu C, Géry B, Babin E and Thariat J: Systemic treatments of metastatic or locally recurrent adenoid cystic carcinoma of the head and neck, a systematic review. Bull Cancer 106: 923-938, 2019 (In French).

18. Qi W, Guo J, Wu S, Su B, Zhang L, Pan J and Zhang J: Synergistic effect of nanosecond pulsed electric field combined with low-dose of pingyangmycin on salivary adenoid cystic carcinoma. Oncol Rep 31: 2220-2228, 2014

19. Vasan N, Baselga J and Hyman DM: A view on drug resistance in cancer. Nature 575: 299-309, 2019.

20. Bi CL, Fang JS, Chen FH, Wang YJ and Wu J: Chemoresistance of CD133(+) tumor stem cells from human brain glioma. Zhong Nan Da Xue Xue Bao Yi Xue Ban 32: 568-573, 2007 (In Chinese)

21. Attia S, Atwan N, Arafa M and Shahin RA: Expression of CD133 as a cancer stem cell marker in invasive gastric carcinoma. Pathologica 111: 18-23, 2019

22. Barzegar Behrooz A, Syahir A and Ahmad S: CD133: Beyond a cancer stem cell biomarker. J Drug Target 27: 257-269, 2019.

23. Aghajani M, Mansoori B, Mohammadi A, Asadzadeh Z and Baradaran B: New emerging roles of CD133 in cancer stem cell: Signaling pathway and miRNA regulation. J Cell Physiol 234: 21642-21661, 2019.
24. Jia Q, Zhang X, Deng T and Gao J: Positive correlation of Oct4 and ABCG2 to chemotherapeutic resistance in CD90(+)CD133(+) liver cancer stem cells. Cell Reprogram 15: 143-150, 2013.

25. Sarvi S, Mackinnon AC, Avlonitis N, Bradley M, Rintoul RC, Rassl DM, Wang W, Forbes SJ, Gregory CD and Sethi T: CD133 ${ }^{+}$ cancer stem-like cells in small cell lung cancer are highly tumorigenic and chemoresistant but sensitive to a novel neuropeptide antagonist. Cancer Res 74: 1554-1565, 2014.

26. van Rhenen A, Feller N, Kelder A, Westra AH, Rombouts E, Zweegman S, van der Pol MA, Waisfisz Q, Ossenkoppele GJ and Schuurhuis GJ: High stem cell frequency in acute myeloid leukemia at diagnosis predicts high minimal residual disease and poor survival. Clin Cancer Res 11: 6520-6527, 2005.

27. Bertolini G, Roz L, Perego P, Tortoreto M, Fontanella E, Gatti L, Pratesi G, Fabbri A, Andriani F, Tinelli S, et al: Highly tumorigenic lung cancer $\mathrm{CD} 133^{+}$cells display stem-like features and are spared by cisplatin treatment. Proc Natl Acad Sci USA 106: 16281-16286, 2009.

28. Lee TK, Castilho A, Cheung VC, Tang KH, Ma S and Ng IO: $\mathrm{CD} 24(+)$ liver tumor-initiating cells drive self-renewal and tumor initiation through STAT3-mediated NANOG regulation. Cell Stem Cell 9: 50-63, 2011.

29. Kong FB, Deng QM, Deng HQ, Dong CC, Li L, He CG, Wang XT, $\mathrm{Xu}$ S and Mai W: Siva 1 regulates multidrug resistance of gastric cancer by targeting MDR1 and MRP1 via the NF-kB pathway. Mol Med Rep 22: 1558-1566, 2020.

This work is licensed under a Creative Commons Attribution-NonCommercial-NoDerivatives 4.0 International (CC BY-NC-ND 4.0) License. 